\title{
Capsaicin receptors are colocalized with sweet/bitter receptors in the taste sensing cells of circumvallate papillae
}

\author{
Young Wha Moon $\cdot$ Jong-Ho Lee $\cdot$ Sang Bae Yoo \\ Jeong Won Jahng
}

Received: 25 September 2009/ Accepted: 24 November 2009/Published online: 18 December 2009

(C) Springer-Verlag 2009

\begin{abstract}
We examined co-localization of vanilloid receptor (VR1) with sweet receptors T1R2, T1R3, or bitter receptor T2R6 in taste receptor cells of rat circumvallate papillae. Tissue sections of rat circumvallate papillae were doubly reacted with anti-VR1 antibodies and anti-T1R2, anti-T1R3 or anti-T2R6 antibodies, using double-immunofluorescence histochemistry technique. Localizations of VR1, T1Rs and T2R6 in the vallate taste cells containing $\alpha$-gustducin were also examined. VR1 immunoreactivities (-ir) were observed in subsets of taste cells in the circumvallate papillae, and $96-99 \%$ of the vallate taste cells exhibiting T1R2-, T1R3- or T2R6-ir co-exhibited VR1-ir. Approximately half of T2R6-ir cells ( $49 \%)$, and 50-58\% of T1Rs-ir cells, co-exhibited $\alpha$-gustducin-ir in the vallate taste buds. About $58 \%$ of VR1-ir cells in the vallate exhibited $\alpha$-gustducin-ir as well. Results support the idea that capsaicin may interact with the transduction pathways of sweet and bitter taste stimuli, possibly in mediation of its receptor VR1 localized in taste receptor cells. Additionally, the partial co-localization of $\alpha$-gustducin with VR1 suggests that a tentative modulatory function of capsaicin in sweet and bitter transductions in the rat circumvallate comprises of both $\alpha$-gustducin-mediated and non-mediated transduction pathways.
\end{abstract}

\footnotetext{
Y. W. Moon

Department of Natural Science, College of Medicine,

The Catholic University of Korea, Seoul 137-701, Korea

J.-H. Lee $\cdot$ S. B. Yoo $\cdot$ J. W. Jahng $(\bowtie)$

Department of Oral and Maxillofacial Surgery,

Dental Research Institute, Seoul National University

School of Dentistry, Seoul 110-768, Korea

e-mail: jwjahng@snu.ac.kr
}

Keywords Vanilloid receptor - Circumvallate papillae . Taste perception - Tongue

\section{Introduction}

Capsaicin (8-methyl- $N$-vanillyl-6-non-enamide) is the principle active component of chili peppers. Pharmacologic doses of capsaicin evoke burning and painful sensations when capsaicin interacts with its receptors located at sensory nerve endings [2, 37]. Capsaicin receptor, the vanilloid receptor subtype 1 (VR1), is a non-selective cation channel, predominantly expressed by peripheral sensory neurons, which plays a key role in the detection of noxious painful stimuli $[5,12,33]$, many of which also cause pain in humans $[15,31,34]$. However, capsaicin at lower concentration elicits a pleasant warm sensation in the mouth, and this response is suggested to be due to interaction of capsaicin with taste receptor cells [38], rather than sensory neurons. Though the effects of capsaicin on sensory nerve endings are well known, direct effects of capsaicin on taste receptor cells have been poorly understood. Although VR1 mRNA expression was detected by RT-PCR technique and VR1 immuno-positive nerve fibers have been demonstrated in the taste papillae [14, 16, 19], the existence of VR1 in taste receptor cells had not been reported until very recently we have reported the immunohistochemical localization of VR1 in the taste cells of rat circumvallate papillae [10]. In vitro study had reported that capsaicin inhibits the potassium currents of taste receptor cells [23]. This report in conjunction with our previous finding [10] suggests enhancing or modifying effect of capsaicin on taste perception in vivo, possibly in mediation of its receptor VR1 localized in taste receptor cells. 
It has been reported that capsaicin suppresses human responses to sweet, bitter and umami [8, 9, 24, 29]. Although the mechanisms underlying these observations remain unclear, capsaicin may interact with the transduction pathways of other taste stimuli. Indeed, it was reported that capsaicin can elicit bitter sensation on their own and this can be effectively suppressed by sucrose [9]. Furthermore, we have observed a modulatory effect of intra-oral capsaicin on the consumption of sweet solutions in rats [10]. In this study, we examined co-localization of VR1 with sweet receptors T1R2, T1R3, or bitter receptor T2R6 in the taste cells of rat circumvallate papillae, in order to further support a tentative modulatory role of capsaicin in sweet and/or bitter transduction pathways, directly in taste receptor cells.

\section{Materials and methods}

\section{Animals}

Male Sprague-Dawley rats (200-250 g) were purchased (Samtako Bio, Osan, Korea) and maintained in a specific pathogen-free (SPF) barrier zone with the constantly controlled temperature $\left(22 \pm 1^{\circ} \mathrm{C}\right)$ and humidity $(55 \%)$ on a 12-h light-dark cycle (lights-on at 07:00 h) in the Seoul National University Animal Facility Breeding Colony. Rats had ad libitum access to standard rodent chow (Purina Rodent Chow, Purina Co., Seoul, South Korea) and tap water, and were habituated in the animal colony at least for a week. Animals were cared for according to The Guide for Animal Experiments, 2000, edited by the Korean Academy of Medical Sciences, which is consistent with the NIH Guideline Guide for the Care and Use of Laboratory Animals, 1996 revised. All animal protocols were approved by the Committee for the Care and Use of Laboratory Animals at Seoul National University.

\section{Double-fluorescence immunohistochemistry}

Rats $(n=8)$ were anesthetized with an overdose of sodium pentobarbital. When completely anesthetized, transcardiac perfusion was performed with heparinized isotonic saline $\left(0.9 \% \mathrm{NaCl}, 0.5 \% \mathrm{NaNO}_{2}\right)$ followed by ice-cold fixative ( $4 \%$ paraformaldehyde in $0.1 \mathrm{M}$ sodium phosphate buffer, $\mathrm{pH}$ 7.2). Tissues of circumvallate papillae $(\mathrm{CV})$ were rapidly dissected and post-fixed with the same fixative for 4-5 h. After dehydration in graded alcohols, the fixed tissues were then embedded in wax (Polyethylene glycol 400 diesterate, Polyscience, Warrington, PA, USA). Tissue sections were obtained at 8- $\mu \mathrm{m}$ thickness using a microtome (Leica RM 2135), and every fifth sections were deposited on gelatin-coated slides. After de-waxing with xylene and hydration in graded alcohols, endogenous peroxidases were inactivated by treating the tissue sections with $1.5 \%$ hydrogen peroxide for $30 \mathrm{~min}$. Sections were then washed twice with $0.1 \mathrm{M}$ sodium phosphate buffered saline (PBS) for $15 \mathrm{~min}$ each, and incubated with normal donkey serum (1:50 dilution, Jackson ImmunoResearch Lab, USA) for $30 \mathrm{~min}$ at room temperature. Each section was doubly incubated with rat anti-rabbit VR1 antibodies $(1: 300$ or 1:500 dilution, Sigma-Aldrich, St Louis, MO, USA) and rat anti-goat T1R2 antibodies(1:200 dilution, Santa Cruz Biotechnology, CA, USA), human anti-goat T1R3 antibodies (1:300 dilution, Santa Cruz Biotechnology, CA, USA), or mouse anti-goat T2R6 antibodies (1:300 dilution, Santa Cruz Biotechnology, CA, USA) overnight at $4^{\circ} \mathrm{C}$. Rat anti-rabbit $\mathrm{G}$ - $\alpha$-gustducin $(1: 1,000$ dilution, Santa Cruz Biotechnology, USA) was applied to another set of tissue sections together with human anti-goat VR1 antibodies (1:20 or 1:50 dilution, Santa Cruz Biotechnology, USA) or rat anti-goat T1R2 antibodies(1:200 dilution, Santa Cruz Biotechnology, CA, USA) or human anti-goat T1R3 antibodies (1:300 dilution, Santa Cruz Biotechnology, CA, USA) or mouse anti-goat T2R6 antibodies (1:300 dilution, Santa Cruz Biotechnology, CA, USA) overnight at $4^{\circ} \mathrm{C}$. Tissue sections were washed twice in PBS, and the bound primary antibodies were visualized by incubating with $\mathrm{Cy} 3$ conjugated to donkey anti-goat IgG (1:1,000 dilution, Jackson ImmunoResearch Lab, USA) and Alexa Fluor 488 conjugated to donkey anti-rabbit $\operatorname{IgG}(1: 1,000$ dilution, Molecular Probes, USA) for $1 \mathrm{~h}$ at room temperature. Stained tissue sections were washed in PBS, mounted with Prolong Gold antifade reagent (Invitrogen, OR, USA), and then observed under confocal laser scanning microscope (Carl Zeiss, LSM510 META). Immuno-positive cells (200-250 cells per rat) were hand-counted from the confocal microscopic images. Tissue sections for the negative control were processed parallel omitting primary antibodies.

\section{Results}

Most cells in the circumvallate papillae containing T1R2, T1R3 or T2R6 appeared to co-express VR1 (Fig. 1a). Quantitative analysis showed that $96-99 \%$ of the vallate taste cells exhibiting T1R2-, T1R3- or T2R6-ir co-exhibit VR1-ir (Fig. 1b). Some of the vallate taste cells exhibiting T1Rs-, T2R6- or VR1-ir appeared to co-express $\alpha$-gustducin (Fig. 2a). About half of T2R6-ir cells ( $\sim 49 \%)$, and $50-58 \%$ of T1Rs-ir cells, co-exhibited $\alpha$-gustducin-ir in the vallate taste buds (Fig. 2b). Similarly, $\sim 58 \%$ of VR1-ir cells in the vallate exhibited $\alpha$-gustducin-ir. 


\section{A}
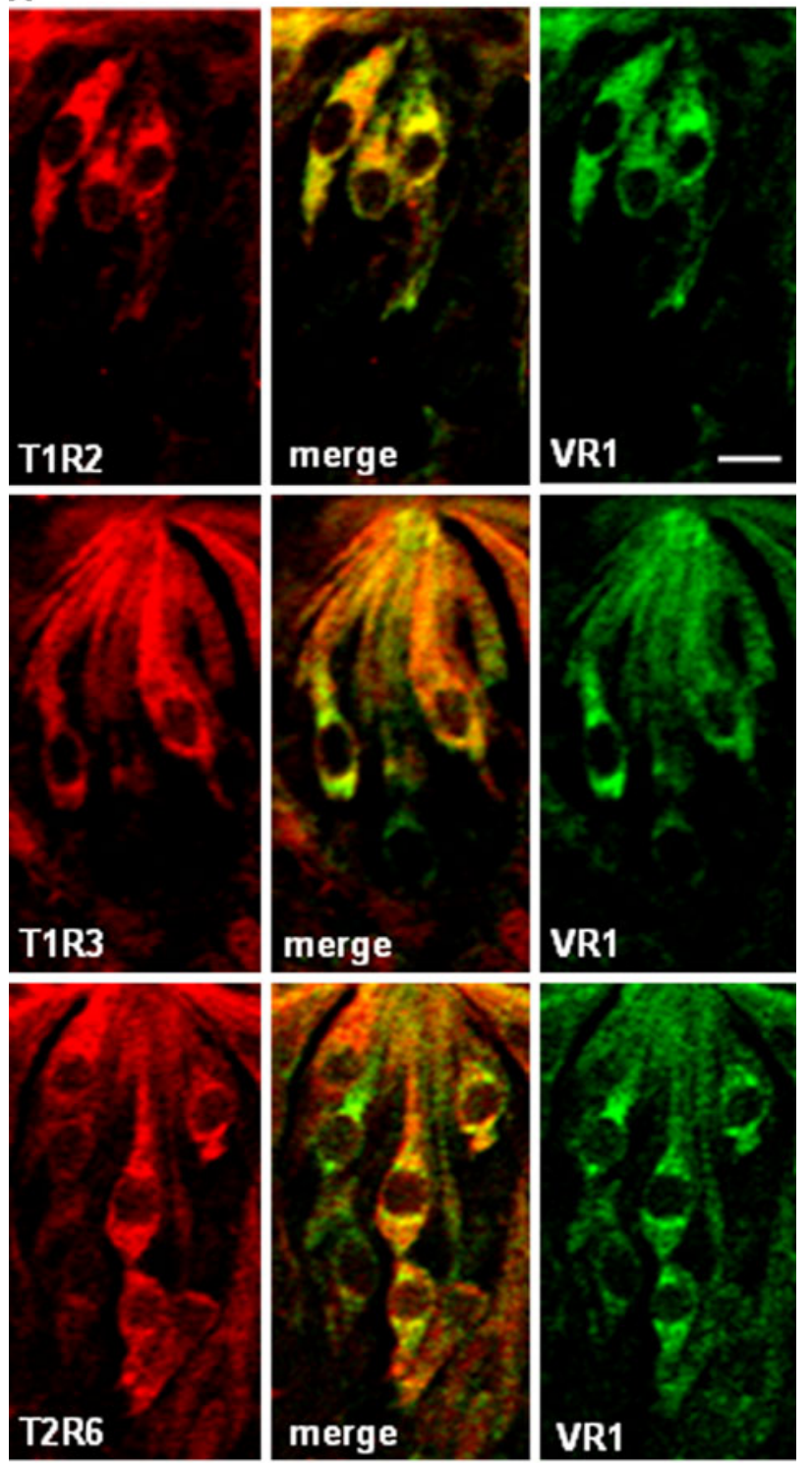

B

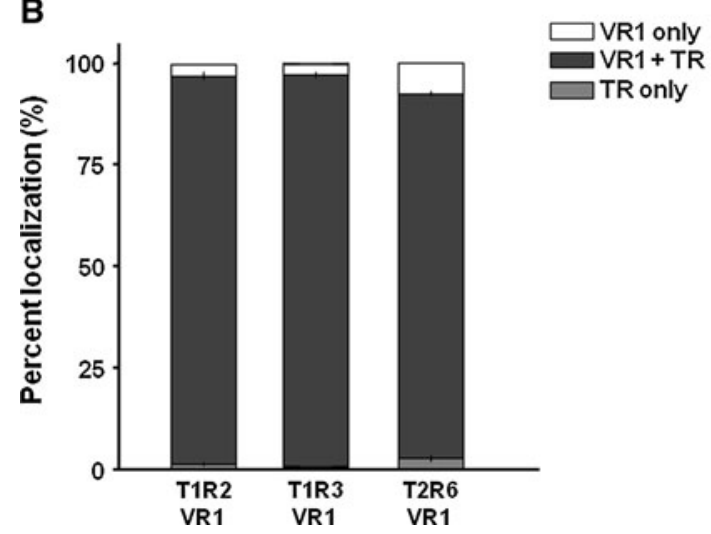

Fig. 1 Double-fluorescence immunohistochemistry of T1R2, T1R3 or T2R6 with VR1 in the rat circumvallate papillae (a), and the quantitative analysis of the co-localization of VR1 with sweet or bitter receptors (b). TR taste receptors, Scale bars $10 \mu \mathrm{m}$
A
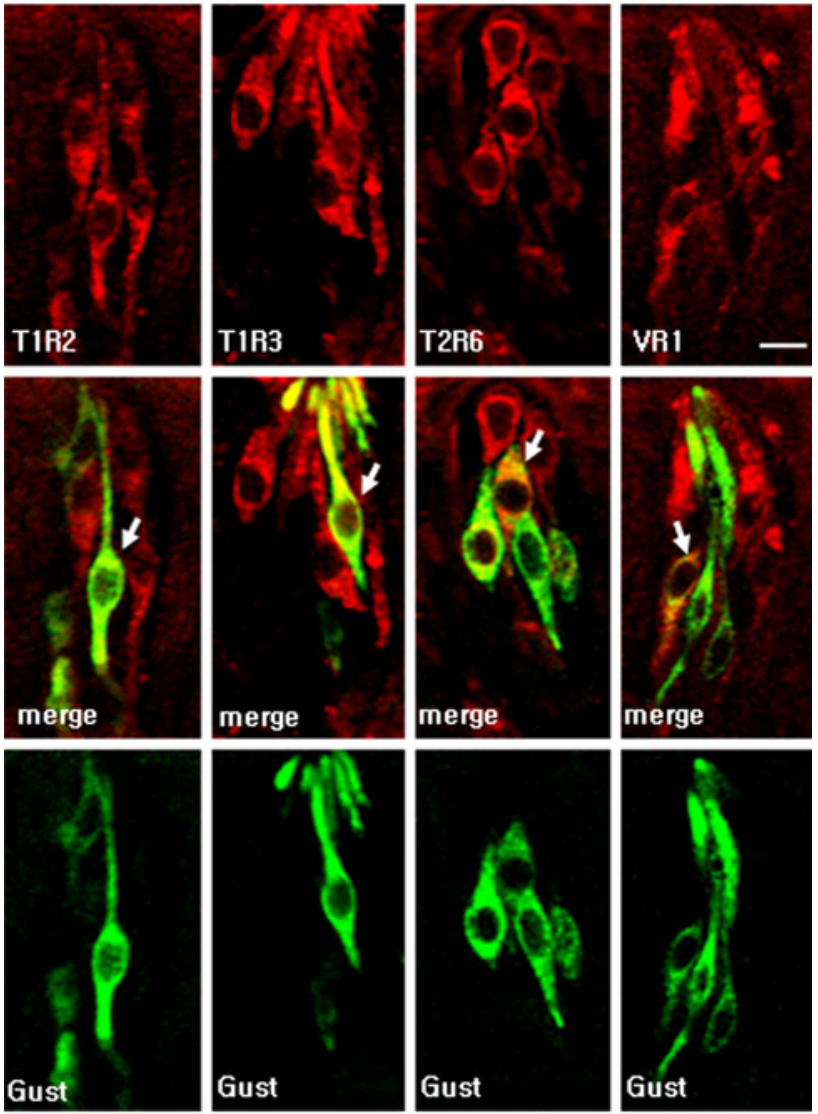

merge

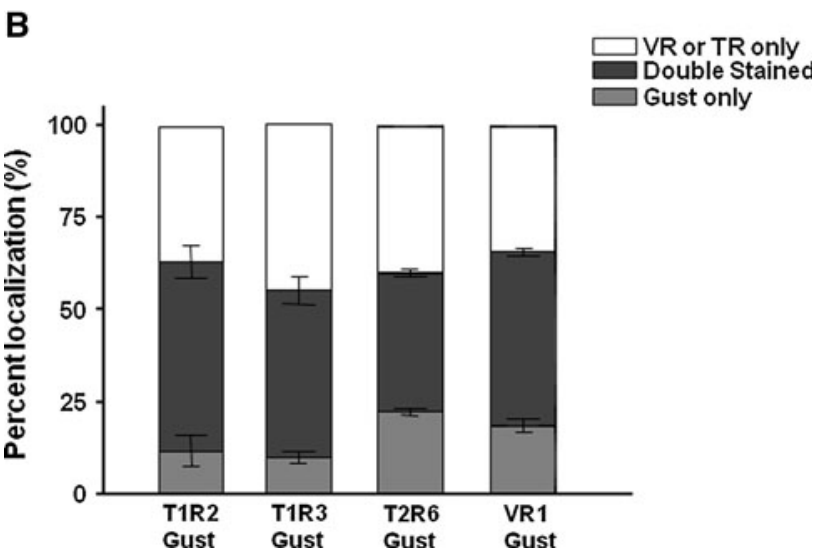

Fig. 2 Double-fluorescence immunohistochemistry of VR1, T1R2, T1R3 or T2R6 with $\alpha$-gustducin in rat circumvallate papillae (a), and the quantitative analysis of the co-localization of $\alpha$-gustducin in the taste receptor cells containing VR1, T1Rs or T2R6 (b). Arrows indicate doubly stained cells. TR taste receptors, Gust $\alpha$-gustducin, Scale bars $10 \mu \mathrm{m}$

\section{Discussion}

It has been reported that VR1 is predominantly expressed by peripheral sensory neurons, which plays a key role in the detection of noxious painful stimuli $[5,12,15,31,33$, 34]. Contrary to the effects of capsaicin on sensory nerve 
endings that are well known, direct effects of capsaicin on taste receptor cells have been poorly understood. Previous studies have reported a direct interaction of capsaicin with taste receptor cells, suggesting that perception of capsaicin could be a chemesthetic response via VR1 in taste cells $[23,38]$. This seemed to be more possible, especially when capsaicin at lower concentration elicits a pleasant sensation in the mouth [38]. We have recently reported that repeated oral exposure to capsaicin at an edible concentration increases the consumption of sweet solutions in rats, and this was accompanied by decreased mRNA expression of sweet receptors in the circumvallate papillae [10]. T1R2 and T1R3 form a broadly tuned sweet receptor, responding to natural sugars and artificial sweeteners, and are strongly expressed in circumvallate papillae [13, 18, 20-22, 27]. In this study, VR1-ir was co-localized in most taste cells in the circumvallate papillae exhibiting immunoreactivity against T1R2 or T1R3. Taken together, it is likely that capsaicin modulates sweet perception pathway directly in taste receptor cells via its receptor VR1. Human studies have reported that capsaicin suppresses the responses not only to sweet, but also to bitter taste [8, 9, 24, 29]. It has been reported that many taste cells in the rodent vallate richly express $\mathrm{T} 2 \mathrm{Rs}$, the bitter receptors [1, 17]. In this study, $\sim 96 \%$ of the vallate taste cells exhibiting T2R6-ir exhibited VR1-ir as well, suggesting a tentative modulatory effect of capsaicin on bitter taste transmission, directly in taste receptor cells. Therefore, it is concluded that capsaicin may interact with the transduction pathways of sweet and bitter taste stimuli, possibly in mediation of its receptor VR1 localized in taste cells.

In addition to receptor proteins, downstream signaling effectors play important roles in taste transduction. One of these effectors is a subunit of $\mathrm{G}$ protein, the $\alpha$-gustducin, which is present in some taste cells in all taste buds regions [3]. Mice lacking the $\alpha$-gustducin protein are defective in their ability to detect sweet, bitter, and umami tastants $[4,25,26,35,36]$, suggesting that $\alpha$-gustducin has impact on both the transduction pathways of $G$ protein coupled receptors T1Rs and T2Rs. However, a recent study has reported that lack of $\alpha$-gustducin does not significantly affect short term preference to sweet tastes in mice [7], suggesting that $\alpha$-gustducin is not necessary for sweet taste transduction. In this study, we have demonstrated that about half (50-58\%) of T1R2- or T1R3-ir cells in the rat circumvallate papillae co-exhibit $\alpha$-gustducin-ir. Co-localization of sweet receptors with $\alpha$-gustducin has been hardly reported in rats. In mice, while most taste cells in the fungiform papillae expressing T1R2 or T1R3 co-express $\alpha$-gustducin [30], fewer numbers of cells in the circumvallate papillae containing T1R2 or T1R3 co-express $\alpha$-gustducin $[17,21,30,32]$. Although it appears that more number of sweet sensing cells in the circumvallate papillae co-express $\alpha$-gustducin in rats than in mice, the partial co-localization of T1Rs with $\alpha$-gustducin in the circumvallate of mice and rats further supports the idea that $\alpha$-gustducin is not necessary for sweet taste transduction. A recent study has reported that sweet taste transduction may rely on different downstream transduction elements in posterior (vallate) and anterior taste papillae [32].

It has been reported that most or all kinds of the bitter receptors (T2Rs) are co-expressed in the same cell population on the tongue that does not contain the sweet receptors T1Rs [1, 22], suggesting that the taste cells containing $\mathrm{T} 2 \mathrm{Rs}$ could recognize a wide range of structurally diverse bitter compounds by virtue of having various kinds of bitter receptors. Previous studies have reported that T2Rs are co-expressed with $\alpha$-gustducin in many taste cells of the circumvallate papillae [1, 17], and functional implications of $\alpha$-gustducin in bitter taste transduction have been reported $[1,6]$. They argued that $\alpha$-gustducin may play as general effectors in bitter transduction in rodents. However, in this study, only a half of T2R6-ir cells ( $\sim 49 \%$ ) co-exhibited $\alpha$-gustducin-ir in the rat circumvallate. A recent in vitro study has reported that different T2Rs display different affinities and selectivities among the G-proteins tested [28], raising the possibility that in vivo, different T2Rs may preferentially signal through different pathways. Sainz and colleagues [28] have suggested that there are at least two classes of bitter receptors: those that are fairly specific, recognizing only a few structurally related bitter compounds, and those like hT2R7, that are broadly tuned bitter receptors. A recent study has demonstrated the evidence for two different populations of bitter responsive taste cells in mice [11]. Taken together, the present result indicates that $\alpha$-gustducin is not the general effectors mediating bitter transduction. It is plausible that besides $\alpha$-gustducin, some other downstream signaling pathway also mediate bitter transductions by different bitter stimuli in rats.

Lastly, we have demonstrated that a little more than a half $(\sim 58 \%)$ of VR1 containing taste cells in the rat circumvallate co-express $\alpha$-gustducin. The partial co-localization of $\alpha$-gustducin with VR1 in the rat circumvallate suggests that a tentative modulatory function of capsaicin in sweet and bitter transductions discussed above comprises of both $\alpha$-gustducin-mediated and non-mediated transduction pathways. Studies on the underlying mechanism of capsaicin interaction with sweet and bitter transductions are currently underway in our laboratories.

Acknowledgments This study was supported by a grant from the Brain Research Center of the 21st Century Frontier Research Program (JWJ; 2009K001269) funded by the Korea Government (Ministry of Education, Science and Technology), and a grant of the Korea Health 21 R\&D Project, Ministry of Health \& Welfare, Republic of Korea (JHL; A080863). 


\section{References}

1. Adler E, Hoon MA, Mueller KL, Chandrashekar J, Ryba NJP, Zuker CS (2000) A novel family of mammalian taste receptors. Cell 100:693-702

2. Bevan S, Szolcsányi J (1990) Sensory neuron-specific actions of capsaicin: mechanisms and application. Trends Pharmacol Sci $11: 330-333$

3. Boughter JD Jr, Pumplin DW, Yu C, Christy RC, Smith DV (1997) Differential expression of alpha-gustducin in taste bud populations of the rat and hamster. J Neurosci 17:2852-2858

4. Caicedo A, Pereira E, Margolskee RF, Roper SD (2003) Role of the G-protein subunit a-gustducin in taste cell responses to bitter stimuli. J Neurosci 23(30):9947-9952

5. Caterina MJ, Schumacher MA, Tominaga M, Rosen TA, Levin JD, Julius D (1997) The capsaicin receptor: a heat-activated ion channel in the pain pathway. Nature 380:816-824

6. Chandrashekar J, Mueller KL, Hoon MA, Adler E, Feng L, Guo W, Zuker CS, Ryba NJ (2000) T2Rs function as bitter taste receptors. Cell 100:703-711

7. Glendinning JI, Bloom LD, Onishi M, Zheng KH, Damak S, Margolskee RF, Spector AC (2005) Contribution of a-gustducin to taste-guided licking responses of mice. Chem Senses 30:299316

8. Green BG, Hayes JE (2003) Capsaicin as a probe of the relationship between bitter taste and chemesthesis. Physiol Behav 79:811-821

9. Green BG, Schullery MT (2003) Stimulation of bitterness by capsaicin and menthol: differences between lingual areas innervated by the glossopharyngeal and chorda tympani nerves. Chem Senses 28:45-55

10. Gu XF, Lee JH, Yoo SB, Moon YW, Jahng JW (2009) Intra-oral pre-treatment with capsaicin increases consumption of sweet solutions in rats. Nutr Neurosci 12(4):149-154

11. Hacker K, Laskowski A, Feng L, Restrepo D, Medler K (2008) Evidence for two populations of bitter responsive taste cells in mice. J Neurophysiol 99:1503-1514

12. Hayes P, Meadows HJ, Gunthorpe MJ, Harries MH, Duckworth DM, Cairns W, Harrison DC, Clarke CE, Ellington K, Prinjha RK et al (2000) Cloning and functional expression of a human orthologue of rat vanilloid receptor-1. Pain 88:205-215

13. Hoon MA, Adler E, Lindemeier J, Battey JF, Ryba NJ, Zuker CS (1999) Putative mammalian taste receptors: a class of tastespecific GPCRs with distinct topographic selectivity. Cell 96:541-551

14. Ishida Y, Ugawa S, Ueda T, Murakami S, Shimada S (2002) Vanilloid receptor subtype-1 (VR1) is specifically localized to taste papillae. Mol Brain Res 107:17-22

15. Jones NG, Slater R, Cadiou H, McNaughton P, McMahon SB (2004) Acid-induced pain and its modulation in humans. J Neurosci 24:10974-10979

16. Kido MA, Muroya H, Yamaza T, Terada Y, Tanaka T (2003) Vanilloid receptor expression in the rat tongue and palate. J Dent Res 82:393-397

17. Kim MR, Kusakabe Y, Miura H, Shindo Y, Ninomiya Y, Hino A (2003) Regional expression patterns of taste receptors and gustducin in the mouse tongue. Biochem Biophys Res Commun 312:500-506

18. Kitagawa M, Kusakabe Y, Miura H, Ninomiya Y, Hino A (2001) Molecular genetic identification of a candidate receptor gene for sweet taste. Biochem Biophys Res Commun 283:236-242
19. Liu L, Simon SA (2001) Acidic stimuli activates two distinct pathways in taste receptor cells from rat fungiform papillae. Brain Res 923:58-70

20. Max M, Shanker YG, Huang L, Rong M, Liu Z, Campagne F, Weinstein H, Damak S, Margolskee RF (2001) Tas1r3, encoding a new candidate taste receptor, is allelic to the sweet responsiveness locus Sac. Nat Genet 28:58-63

21. Montmayeur JP, Liberles SD, Matsunami H, Buck LB (2001) A candidate taste receptor gene near a sweet taste locus. Nat Neurosci 4:492-498

22. Nelson G, Hoon MA, Chandrashekar J, Zhang Y, Ryba NJ, Zuker CS (2001) Mammalian sweet taste receptors. Cell 106:381-390

23. Park K, Brown PD, Kim YB, Kim J-S (2003) Capsaicin modulates $\mathrm{K}+$ currents from dissociated rat taste receptor cells. Brain Res 962:135-143

24. Prescott J, Stevenson RJ (1995) Effects of oral chemical irritation on tastes and flavors in frequent and infrequent users of chili. Physiol Behav 58:1117-1127

25. Ruiz-Avila L, Wong G, Damak S, Margolskee RF (2001) Dominant loss of responsiveness to sweet and bitter compounds caused by a single mutation in a-gustducin. Proc Natl Acad Sci USA 98:8868-8873

26. Ruiz CJ, Wray K, Delay E, Margolskee RF, Kinnamon SC (2003) Behavioral evidence for a role of alpha-gustducin in glutamate taste. Chem Senses 28:573-579

27. Sainz E, Korley JN, Battey JF, Sullivan SL (2001) Identification of a novel member of the T1R family of putative taste receptors. J Neurochem 77:896-903

28. Sainz E, Cavenagh MM, Gutierrez J, Battey JF, Northup JK, Sullivan SL (2007) Functional characterization of human bitter taste receptors. Biochem J 403:537-543

29. Simons CT, O'Mahony M, Carstens E (2002) Taste suppression following lingual capsaicin pre-treatment in humans. Chem Senses 27:353-365

30. Stone LM, Barrows J, Finger TE, Kinnamon SC (2007) Expression of T1Rs and gustducin in palatal taste buds of mice. Chem Senses 32:255-262

31. Szallasi A, Blumberg PM (1999) Vanilloid (capsaicin) receptors and mechanisms. Pharmacol Rev 51:159-212

32. Tizzano M, Dvoryanchikov G, Barrows JK, Kim SJ, Nirupa Chaudhari N, Finger TE (2008) Expression of Galpha14 in sweettransducing taste cells of the posterior tongue. BMC Neurosci 9:110

33. Tominaga M, Caterina MJ, Malmberg AB, Rosen TA, Gilbert H, Skinner K, Raumann BE, Basbaum AI, Julius D (1998) The cloned capsaicin receptor integrates multiple pain-producing stimuli. Neuron 21:531-543

34. Trevisani M, Smart D, Gunthorpe MJ, Tognetto M, Barbieri M, Campi B, Amadesi S, Gray J, Jerman JC, Brough SJ, Owen D, Smith GD, Randall AD, Harrison S, Bianchi A, Davis JB, Geppetti P (2002) Ethanol elicits and potentiates nociceptor responses via the vanilloid receptor-1. Nat Neurosci 5:546-551

35. Wong GT, Gannon KS, Margolskee RF (1996) Transduction of bitter and sweet taste by gustducin. Nature 381:796-800

36. Wong GT, Ruiz-Avila L, Ming D, Gannon KS, Margolskee RF (1996) Biochemical and transgenic analysis of gustducin's role in bitter and sweet transduction. Cold Spring Harbor Symp Quant Biol 61:173-184

37. Wood J (1993) Capsaicin in the study of pain. Academic Press, London, pp 27-42

38. Yoshii K, Matui T (1994) Taste response of bullfrog to pungent stimuli. Brain Res 637:68-72 